\title{
Oral Traditions: Method to Adoptation of Construction of the History of Non-Literate Tribes
}

\author{
Tana Showren
}

\begin{abstract}
Studies in oral tradition, covering on contemporary field works are making evident of the profound relationship between oral tradition practitioners and stakeholders give us live to as human beings. This article seeks to explore the emerging field of oral tradition method and various forms of cultural expression in the study of humankind experience in both past and present non-literate tribes. The ways we are shaped by education as well by training significantly influence the ways we understand and interpret the worldview of the non-literate societies. The cultural expression and manifestations are strongly embedded and internalised which often eluded researcher making them to present inaccurate and misnomer interpretation of the indigenous people. The article also attempts to study a technique and methods with interdisciplinary focus for studies in oral tradition of the non-literate tribes, as an alternative methodology for historical research. This would definitely depart from conventional method of research so far employed on to investigate, interpret and analyses the tribes' histories of North East India. In this endeavour, researcher will get a firsthand knowledge of incorporating legends, fairy tales, folklores, folksongs, music, mythology, rhapsodies and all facets of storytelling into construction of the history of nonliterate tribes. Such investigation will establish the linkage between verbal communication and cultural objects maintained by the people as fund of knowledge for the posterity.
\end{abstract}

Index Terms-Aabhu thanyi, acquired cultural myths, illiteracy, nyubh, sebbe.

\section{INTRODUCTION}

The written word is often elevated above the oral, the written documents generally much preferred as evidence to oral tradition, and written sources given more concentration than oral ones whereas such sources are actually derived from oral communication. The grounds for this elevation is, one suspects, more a matter of inherited suppositions and beliefs than of individual thought about the nature of the written words. Oral traditions have more positive associations and the term 'orality' has been conceived to avoid the obvious negative connotations of 'illiteracy'. Literate or illiterate, we are our memories. We try to shape our futures in the light of past experience [1]. The value of oral traditions and communications are now more readily recognised as non-written sources and gained respectability for social scientists and historians these days. For many people, oral traditions and verbal communications still

Manuscript received September 22, 2013; revised November 28, 2013 This work is part of research project on Oral Traditions: Archiving and Compiling the Histories of Arunachal Pradesh, India.

Tana Showren is with the Department of History, Rajiv Gandhi University, Rono Hills, Doimukh-791112, District Papum Pare, Arunachal Pradesh, India (e-mail: tana.showren@rgu.ac.in). suggests crude characteristics or backwardness, yet both are in fact common enough even in the modern world or the rediscovery of folklores, legends, myths, culture, folk traditions and indigenous institutions. In strict sense of origin of sources of knowledge orality is the basic human mode of communication, and although peoples all over the world now use literate means to represent pastness [1]. The two spheres of oral communication and literacy are generally kept separate, regarded as completely distinct, and 'literate societies' strictly distinguished from 'non-literate societies', which clear-cut characteristics attributed to each.

\section{BODY}

Traditionally, professional researchers have based their findings on strictly quantifiable data, generally obtained through the use of standardised tests, interview schedules, or survey that have been designed by the scholars. Usually, there is an unwritten assumption that to be valid a research must be as close as possible to being an empirical design. Most of us share this perception because of our training at the doctoral level, although we are aware that it is seldom that the real world will meet the principle of an empirical research method. Even when well-structured results are obtained, hypotheses tested, and the results stated, we sometimes have the thinking that the data is not giving us a full picture of what is going on in reality. In other words, the feelings that dilettante researcher present is often of absolutely no use to the professional practitioner. There is difficulty in bridging the gap between the real world of people history and the researches that the well-trained and well-equipped methods of researchers could produced. Owing to this, there is an increasing interest in research methodology that would give a paradigm shift from the conventional research of scientific rigour to oral traditions method to reconstruct the past history of non-literate tribes of India's eastern most state of Arunachal Pradesh. Before I proceed on to my arguments, it is worthwhile to discuss something about the meaning and definition of oral traditions as defined and explained by hitherto oral traditions practitioners. Many practitioners of oral traditions of the contemporary time have portrayed various meaning of oral traditions according to their understanding and perception of the subject. In 1965, Jan Vansina in his path breaking work, Oral Tradition: A Study in Historical Methodology, defines oral traditions as, "oral traditions consist of all verbal testimonies which are reported statements concerning the past." [2]. Thus, oral traditions are any reported statements, and they are specifically about the past. A prerequisite for oral traditions are that there must be transmission by word of mouth over at least a generation. 
While arguing the complexity of oral traditions, Bruce A. Rosenberg puts it as, "oral traditions are both more specific and less ambiguous communication, because the speaker reinforces his or her specificity of meaning with gesture, expression, intonation, and so on, and various selfcorrecting mechanism of which fixed print is incapable." [3] So, oral traditions are the transmission of cultural items from one generation to next generation. These traditions are heard, stored in memory, and when appropriate, recalled at the moment of subsequent transmission. A noted twentieth century economic historian, Karl Polanyi once said that premarket economy of the pre-literate society was embedded in social institutions of customs and laws, religion and magic [4]. A closer look at the complex nature of oral traditions, R.C.Culley maintains that "oral tradition implies a letter perfect handling on from person to person; on the other hand, oral tradition implies changes occurring in the material [5]. So, the traditions without the aid of writing; for some centuries they were handed down by word of mouth exclusively. It is to be noted that no oral traditions could be properly comprehended unless due account is taken of the social organisations and language of the people concerned as John Fage and David Tait stated that "Oral tradition is often in reality an explanation, in quasi-historical terms, of existing or of currently relevant past social or sociopolitical relationships." [6]. It is argued that the past is viewed from the present, wherever, the present may be located and selected from the past goes into constructing a tradition. While writing about the tradition and the making of history, Romila Thapar, writes that, "a tradition is never handed down intact from generation to generation, however, appealing this idea may seem. Innovation is what gives it vitality. The items selected from the past are often so chosen as to legitimize the values and codes of the present." [7]. It is in this spirit that present article is a modest attempt to explain the significance of oral traditions as methodology to adopt for construction of the past history of non-literate societies of Arunachal Pradesh. Reasons are amply justify that in this part of the country majority of tribes do not have any written records and script to records their own past. Arunachal Pradesh is a home of 26 major tribes and a number of sub-tribes, in which the Monpa, the Khampti and the Memba is having their own scripts while all the Aabhu Thanyi [8] tribes of middle zone of state is absence of their own scripts.

Given the background of foregoing discussion, traditional societies of Arunachal Pradesh offers a conspicuous refutation of rich oral traditions in the form of legends, myths, poems, stories, folklores, folktales and so forth. We are forced to think again about the nature of literacy the role of written record and oral communication by word of mouth. In many respects, the native societies are an oral society. It would seem that indigenous traditional life is gradually disappearing, although the social memory of surviving elders is passing down to the next generations with all limitation. A strict division between oral and literate societies is manifestly inappropriate for the community. Generally, any written histories of the country or region are largely derived from oral traditions; hence, we need to pay a serious attention not merely to the written literature but to explore an alternative source material to write about the non-literate societies. Greater understanding of oral traditions and literacy by social scientists, and the importance of social memory by social anthropologists, now made it particularly necessary to approach these problems with more sophistication and appreciation. In this way, we are to explore the possibility of adopting the oral traditions method to construct and analyse the society, development and transformation of tribes of the state. This would contribute to understanding not only to specific aspects of tribe's history and culture, but to the nature and mechanism of oral traditions in general, its relation to social reconstruction of the non-literate societies. Accordingly, a verbal testimony is the sum of the statements made by any one informant concerning a single series of events, so long as all the statements relate to the same referent. It is thus, includes not only the referent but the tradition that is being related in which all the personal additions made to it by the informant [3]. In many indigenous traditions there are numerous examples of occasional verses or hymns made by an individual teller to invoke the deities and offering propitiations to heal ailing persons in which the nyubh (priests) recounts the past history of clan, phratry and tribe. These traditions are spontaneously recited by the nyubh or elders who are having some supernatural power and special esoteric knowledge without any written records. From this point of view, Jan Vansina argued that there are two types of oral traditions generally maintained by non-literate societies. It is possible to distinguish between two types of traditions which he writes that "one which is fixed form and are learnt by heart and transmitted as they stand, and other which are in free form and not learnt by heart and which everyone transmits in his own way [3]. Therefore, it is implies, the fixed type of tradition is that oral traditions which is in the form of poem, while the free type of tradition is in the form of narrative one. The very words of the poem belong to the tradition, whereas, in the case of the narrative, they are a contribution made by the narrator [3]. In the light of these arguments, the most popular type of oral traditions maintained amongst the tribes of the state is largely in the poetic forms of traditions as well as narrative forms. These two types of oral traditions are being practiced by the Aabhu Thanyi tribes of the state invariably with their own distinct methods of social memories and mnemonic techniques.

As we look at deeper aspects of oral traditions being maintained by the indigenous tribes in relation to their past histories, there are hardly enough study have been done so far. Although, many earlier researchers' inquiries were ranged widely in the matter of anthropology, ethnography, religion and sociology of the tribes; and other vibrant traditions maintained by the peoples were reduced to mere myths. In this way we find a several works done on these non-literate societies found themselves overlapping and tribal world of nature were not seriously taken into account while constructing their past histories. So, there is little systematic attention has so far been paid to either emic or etic researchers to record the oral genres, with the exception of writings of Verrier Elwin and Christopher Von Haimendorf. The basic premise of their writings was swiping generalization and sympathetic views of construction on the native cultures and customs. Such was the earlier inquiries; however, the communities in different 
parts of Arunachal Pradesh have a considerable variety of distinct oral genres relating to common mythical ancestor the Aabhu Thanyi. Despite of some variations in the range of traditions current amongst the people about their common ancestor the Aabhu Thanyi , these tribes, however, maintain a considerable degree of homogeneity and similarity in the terms of culture and customs practices. According to earlier ethnographer's construction on these tribes, there is several factual information and evidences were erroneously recorded as confirmation by intellectual predilection and prejudice. It is perhaps, these writings were more or less devoid of objective and partial by emphasising on sympatric view to the tribal world nature. All arguments to these constructions were justified on the grounds of lack of written records with the tribes. It is reminded us of Leopold Von Ranke's statement which he said, "it requires us to recognise the parties in any historical struggle in their own terms, to understand them before we judge them." [9]. Likewise all these earlier constructed ethnography and history of the tribes were recorded without attempting to understand the intricacies of embedded tribal world and internalised oral traditions in the line of partial and objective interpretation. Now these distorted and concocted historical information are to be re-examined and reconstructed based on the oral traditions data and corroborate with available written material on the tribes. Since social memories were the means to preserve the past unwritten traditions and rich cultural heritage of the community to till date. The significance of doing research on oral traditions of the tribes is now more widely accepted as possible alternative methods to construct the past history of the people. The custodian of these oral traditions and verbal communication are the nyubh or mirri (priests) who play the role of preserving, continuing and memorising these different aspects of tradition practices from generation to generation.

Apart from the above discussion, there are several major areas of research into indigenous dance, cultural objects, symbols, verbal art and theatrical performance generally these forms are rarely presented before any common occasions [10]. These forms of traditions are usually performed under the strict supervision and experts called for specific ritual and religions occasions. Other important cultural objects and properties of these societies are also not open for all the public. These cultural objects and properties are generally kept in secret with the knowledge of keeper only by observing several restriction and taboos. It would seem that in the past, such cultural objects and symbols of historical importance were not taken seriously while studying the oral traditions. We are often inclined to belief; oral traditions are having a single characteristics degree of information. In-depth understanding of the longevity and reliability of oral traditions, we are to appreciate that there are several characteristics dimension attached to each traditions. Hence, all traditional fund of knowledge regarding culture, customs, faith and political institutions are preserved through the sophisticated devices or mechanism of social memories which were transmitted from generation to generation to the present age with special knowledge of esoteric or clairvoyance. Material objects and properties like beads, gongs, swords, vessels, tiara, girdles, bracelets, sebbe (bos gaurus) horn, bells, etc., are moveable cultural objects and properties. These cultural objects and properties are having historical content information; with how they were procured and from which places they have come. On what occasion and ceremony they were obtained. Who was the first owner of these ornaments and precious metals? What are their social value, prestige and importance in the society? What are their price values during peace, dispute and wergild settlement transactions between the inter-clan and inter-village city state feuds and disputes? The histories and legends of these antiques object are well-remembered by the nyubh (priests), elders and jurisprudence experts in the village. These experts would give a live narration of these cultural objects' social value, price and nature of transfer from one owner to another owner; and discussed about the merit and demerit aspects of objects. If one goes on recording detail bio data of these material objects one could keep on recording for two to three days at a stretch. When we closely analyses thee narrations, these cultural objects are used both to symbolise the past and revelation of different nature of social, polity, economic and religious conditions of the tribes. These traditional material objects represent the culture, society, food habits, customs, ritual, traditional trading and barter system prevailed in early societies of a tribe. There are numerous valuable precious material and other paraphernalia items, folksongs and rhapsodies are attached to each of these material objects. They are displayed only before the public when the negotiation for transaction is confirmed between the two parties. The public display of these precious or cultural objects invariably attached a lot of rules and restrictions. When a researcher attempt to understand whole process of negotiation of contradictions and resolutions involved in transaction one could gather the past history and culture of a community in the form of oral traditions. So, in the line of social anthropology, the whole 'words' and 'things' involved to transact one cultural material objects could be treated as valuable historical information to be collected, which in turns serve the natural history collectable oral traditions data. This would definitely strengthen the present research methodology to establish a credible social history of the non-literate tribes of Arunachal Pradesh.

\section{CONCLUSION}

In the conclusion, as we are given to realised that oral traditions could be used for multiple-purpose source material for reconstruction of the past histories of nonliterate tribes. Oral traditions as method to adaptation for construction of the non-literate tribes is a preliminary attempt to address the methodological issue and explore the possibility of using traditions as an alternative tool to do historical research. It is to observe that oral traditions give greater scope to situate the socio-economic and political life of the people with right perspectives and history proper. In the recent time, increasingly oral traditions are becoming a specialised knowledge to understand the indigenous music, dance, culture, customs, art, religion and political institutions of the non-literate peoples. Accordingly, there is a growing interests generated among the native researchers to record various oral traditions and other important cultural objects maintained by the tribes. In fact, in days of yore, this 
field of research was the domain of non-native researchers of anthropologist and social scientists. Now with the line of these emerging new areas of research on non-literate tribes, oral traditions become indispensable source materials to understand and appreciate the tribes' history and culture objectively and meaningfully. As such, we are to explore a new methodology and technique to record whose histories are preserved in the form of living libraries, walking archives and talking texts. Thus, all attempts to understand oral traditions are rooted in assumptions about human actions and the nature of society, even if the holders are unaware of their own beliefs [6]. Most often, we find traditional culture and faith is not recognised as 'culture and faith', by all who study it since it includes beliefs, value and practices. Such traditional culture typically distinguished from one tribe to another, although root genres are the same. Oral traditions of some tribes reflect their cosmological connection and spiritual world view, which is not discernable for any onlooker or layman. Many researchers of earlier often placed these traditions as acquired culture myths over many generations and term them as primitive or obscured mystery. Nonetheless, it help us to understand not just what happened in the past, but how those telling traditions represent what happened and what the peoples think about their past social milieu. Oral traditions method would definitely help in documenting previously undocumented information about rituals, customs, social organisations, myths, legends, indigenous science and knowledge, migration and origin. This will complement or supplement the information already in the records, fill gaps in the ethnographic data, brings out new and previously unknown facts about the tribes. This would provide a new insight into the existing information and correct the distorted accounts on the communities. This would also uncover complexities and intricacies dimension to what was generally perceived as a simple and straightforward recitation of past events and incidents. Thereby, oral traditions and verbal communication becomes a significance source of information for construction of the history of nonliterate tribes. Regardless of the types of oral traditions and verbal communication maintained by a tribe within a given social framework should be appreciated as credible historical information in lieu of hard core archival facts. In a nutshell, oral traditions should be recognised as an alternative tool and technique to document and interpret the past history and culture of the non-literate tribes of Arunachal Pradesh. Although, it sounds plausible to venture into such methods of research but one thing is pretty sure, it is a challenging task to explore and understand the fathom of intricacies and complexities of oral traditions maintained by these tribes. Required skills, expertise and techniques of handling such areas of research entail a specialised knowledge and knowhow on the subject matter. This fund of knowledge, doing oral traditions shall come only through long period of practices and researches.

\section{ACKNOWLEDGEMENT}

The author wishes to thank anonymous peer reviewers and editors for their helpful comments and suggestions.

\section{REFERENCES}

[1] E. Tonkin, Narrating Our Pasts: the Social Construction of Oral History, 1st paperback edition, Cambridge: Cambridge University Press, 1995, ch. 1, pp. 1.

[2] J. Vansina, Oral Tradition: A Study in Historical Methodology, Middlesex, England, Penguin Books, 1973, ch. 19, pp. 19.

[3] B. A. Rosenberg, "The complexity of oral tradition," Oral Tradition vol. 2, no. 1, pp. 73-90, 1987.

[4] K. Polanyi, The Great Transformation, Boston, Beacon Press Boston, 2001, pp.64.

[5] R. C. Cully, "An Approach to the Problem of Oral Tradition," Vetus Testamentum, vol. 13, Fasc. 2, pp. 113-125, April 1963.

[6] E. Tonkin, "Investigating oral tradition," The Journal of African History, Special Issue in Honour of J. D. Fage, vol. 27, no. 2, pp. 203213, 1986.

[7] R. Thapar, Narratives and the Making of History, New Delhi: Oxford University Press, 2000, pp. 4.

[8] T. Showren, "The philosophy of Donyi polo: Reading the consciousness of indigenous religion of arunachal pradesh," in Religion and Society in North East India, Ed. D. Nath, Guwahati, India, DVS Publishers, pp. 219-229, 2011.

[9] L. V. Ranke, Theory and Practice of History, New York: Routledge Taylor \& Francis Group, 2011, part. 1, pp. 2.

[10] M. C. Ross, "Australian aboriginal oral traditions," Oral Tradition, vol. 2, no. 1, pp. 231-71, 1986.

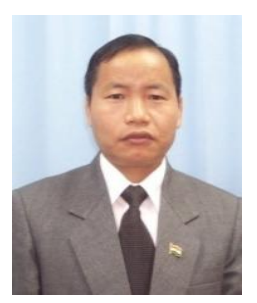

Tana Showren was born on March 1, 1973 at old Midpu village under Doimukh Administrative Circle, District Papum Pare, Arunachal Pradesh, India. He did his master degree in History with specialisation in Ancient Indian History from North Eastern Hill University, Shillong, Meghalaya, India in 1995 and completed the Degree of Doctor of Philosophy in 2005. His publications included: Nyetam of the Aane Donyi (2006), The Nyishi of Arunachal Pradesh: Brief Ethnographic Outline, (2007) and The Nyishi of Arunachal Pradesh: An Ethno historical Study (2009) and numbers of research articles and essay. During the last few years his research interest has been intellectual, ethnography and oral traditions, particularly the study of indigenous institutions, religious and cultural consciousness amongst the non-literate tribes on which he published several articles. The main concern of his research is to comprehend the contemporary technique and methods of oral traditions in historical research in North East India. Prof. Tana Showren teaches in Historical Methods, Oral Traditions and Ancient Societies in the Department of History, Rajiv Gandhi University, Rono Hills, Doimukh-791112, District Papum Pare, Arunachal Pradesh (INDIA). Presently, he is the Chief Co-ordinator of the Oral Tradition Research Project of the Department of History. 